\title{
The optimum timing to wean invasive ventilation for patients with AECOPD or COPD with pulmonary infection
}

This article was published in the following Dove Press journal:

International Journal of COPD

14 March 2016

Number of times this article has been viewed

Yuanlin Song,' Rongchang Chen, ${ }^{2}$ Qingyuan Zhan, ${ }^{3}$ Shujing Chen,' Zujin Luo, ${ }^{4}$ Jiaxian Ou,' Chen Wang ${ }^{3}$

'Department of Pulmonary Medicine, Zhongshan Hospital, Fudan University, Shanghai, ${ }^{2}$ Guangzhou Institute of Respiratory Disease, Guangzhou, ${ }^{3}$ Department of Respiratory and Critical Care Medicine, Beijing China-Japan Friendship Hospital, ${ }^{4}$ Department of Pulmonary Medicine, Chaoyang Hospital, Beijing, People's Republic of China

\section{Video abstract}

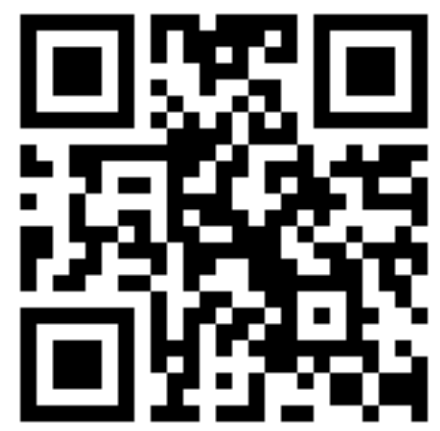

Point your SmartPhone at the code above. If you have a QR code reader the video abstract will appear. Or use: http://youtu.be/KNFo236SFq

Correspondence: Chen Wang Department of Respiratory and Critical Care Medicine, Beijing China-Japan Friendship Hospital, 2 East Yinghua Road, Beijing, 100029 , People's Republic of China Email cyh-birm@263.net

\begin{abstract}
COPD is characterized by a progressive decline in lung function and mental and physical comorbidities. It is a significant burden worldwide due to its growing prevalence, comorbidities, and mortality. Complication by bronchial-pulmonary infection causes $50 \%-90 \%$ of acute exacerbations of COPD (AECOPD), which may lead to the aggregation of COPD symptoms and the development of acute respiratory failure. Non-invasive or invasive ventilation (IV) is usually implemented to treat acute respiratory failure. However, ventilatory support (mainly IV) should be discarded as soon as possible to prevent the onset of time-dependent complications. To withdraw IV, an optimum timing has to be selected based on weaning assessment and spontaneous breathing trial or replacement of IV by non-IV at pulmonary infection control window. The former method is more suitable for patients with AECOPD without significant bronchial-pulmonary infection while the latter method is more suitable for patients with AECOPD with acute significant bronchial-pulmonary infection.
\end{abstract}

Keywords: mechanical ventilation, weaning, spontaneous breathing trial, pulmonary control window, chronic obstructive pulmonary disease

\section{Introduction}

COPD is characterized by a progressive decline in lung function and mental and physical comorbidities (eg, depression, dystrophy, and heart failure). ${ }^{1}$ An exacerbation of COPD is an acute event caused by several factors. To those patients who need ventilator support because of lung infection, weaning mechanical ventilation may be particularly difficult. The clinician's concern is the optimum timing regarding the condition of the patient to wean mechanical ventilation. Unfortunately, there is no consensus or guideline that can give us a distinct conclusion. The aim of this paper is to summarize the evidence-based optimum timing to wean invasive ventilation (IV) in patients with acute exacerbations of COPD (AECOPD) or COPD with pulmonary infection.

\section{COPD and its AECOPD and lung infection in COPD}

COPD is currently a significant burden in the People's Republic of China because of greater risk exposure and uneven medical resource allocation between urban and remote areas. A population-based, cross-sectional survey conducted between 2002 and 2004 suggested a COPD prevalence of $8.2 \%$ among Chinese population over 40 years old. ${ }^{2}$ Other studies reported varied prevalence ranging from 5\% to $13 \% .{ }^{3-6}$ According to the 2004 Global Burden of Disease study, an annual sum of 3 million people die of COPD worldwide. In the People's Republic of China alone, COPD-related mortality was 27.3 in males and 21.3 in females per 100,000 heads according to a national, C. hereby accept the Terms. Non-commercial uses of the work are permitted without any further permission from Dove Medical Press Limited, provided the work is properly attributed. For permission for commercial use of this work, please see paragraphs 4.2 and 5 of our Terms (https://www.dovepress.com/terms.php). 
prospective cohort study conducted between 1990 and 2000. Acute chronic respiratory failure, heart failure, pulmonary infection, pulmonary embolism, cardiac arrhythmia, and lung cancer are the major causes of death in patients with COPD according to a cross-sectional study involving ten European centers. ${ }^{7}$

AECOPD are a common cause of comorbidities and COPDrelated mortality. ${ }^{8-11}$ They are characterized by an increase in the symptoms of dyspnea, sputum volume, and sputum purulence with or without symptoms of upper respiratory infection. ${ }^{12}$ They may also involve worsening of existing symptoms, which require alterations in treatment ranging from antibiotic administration, short courses of oral corticosteroids, and increased bronchodilator usage. ${ }^{13-14}$ Reported AECOPD incidence varied between 2.5 and 3 episodes per patient and year. ${ }^{15}$ Being its major cause, infection accounted for 50\%-70\% AECOPD occurrences worldwide and 80\%-90\% AECOPD occurrences in the People's Republic of China alone. ${ }^{16,17}$ Other predisposing factors include environmental pollution, low temperatures, and concomitant heart failure. ${ }^{18,19}$ Subsequent onset of acute respiratory failure $(\mathrm{ARF})$ may result if $\mathrm{AECOPD}$ are accompanied by bronchial infections, bronchospasm, left ventricular failure, pneumonia, pneumothorax, or thromboembolism. Once ARF occurs, in-patient mortality (4\%-30\%) substantially rise up to $50 \%$ among elderly patients and $11 \%-26 \%$ among intensive care unit (ICU) patients..$^{10,20-23}$

Lung infection other than acute exacerbation is quite common in patients with COPD. The most prevalent form is community-acquired pneumonia. Bronchoscopic studies have shown that at least $50 \%$ of patients have bacteria existence in their lower airway during exacerbations of COPD. ${ }^{1}$ Viruses are also the common etiology of COPD exacerbation next to bacteria. Many patients with COPD who have comorbidities such as hypertension, diabetes, cardiovascular disease are susceptible to lung infection. As stated earlier, lung infection usually accounts for $50 \%-70 \%$ of AECOPD. Not all lung infections in COPD need intensive care. Only the patients who meet the criteria for hospital admission or ICU admission need to be treated in a timely manner.

\section{Treatment for AECOPD/COPD with lung infection patients}

Hospital admission is warranted in an increasing number of patients with AECOPD to prevent ARF onset. ${ }^{24}$ An "ABC approach" involving antibiotics, bronchodilators, and corticosteroids is generally extended to maximize lung function and to reverse the predisposing causes of exacerbations. ${ }^{25}$ Mechanical ventilation is also suggested in $26 \%-74 \%$ of patients with COPD so that the respiratory muscle load may be alleviated to reduce dyspnea and respiratory rate and improve arterial oxygenation, partial pressure of carbon dioxide in arterial blood $\left(\mathrm{PaCO}_{2}\right)$, and $\mathrm{pH} .{ }^{26-28}$ The criteria to start ventilatory support vary but commonly involve the following: 1) moderate to severe dyspnea where accessory muscles are recruited and abdominal breathing prevails; 2) hypercapnic acidosis ( $\mathrm{pH}<7.35)$; 3) tachypnea $(>25 \mathrm{rpm}){ }^{29}$

Non-invasive ventilation (NIV) is validated in patients with early AECOPD because their tolerable coughing ability suggests a stronger need for respiratory muscle fatigue relief rather than airway clearance. It is thus initially provided for patients with severe AECOPD with respiratory acidosis to reduce intubation rate, shorten ICU stay, and decrease patient mortality. Nonetheless, IV is indicated if NIV measures fail to improve clinical manifestation and blood gas parameters 1 hour after implementation. ${ }^{29}$ Any patient with ineffective airway clearance (eg, post-surgical patients or patients with COPD with hypercapnic ARF and pneumonia) needs IV

Table I Indications for non-invasive ventilation (NIV) and invasive ventilation (IV)

\begin{tabular}{ll}
\hline NIV indications & IV indications \\
\hline Clinical manifestations & Cardiac/respiratory arrest \\
Moderate to severe dyspnea & Non-respiratory organ failure \\
Respiratory rate over 25 breaths/min & Severe upper gastrointestinal bleeding \\
Obvious use of accessory muscles & Hemodynamic instability \\
Paradoxical breathing & Unstable cardiac arrhythmia \\
Gas-exchange abnormalities & Facial surgery \\
$\mathrm{PaCO}_{2}$ exceeding $45 \mathrm{mmHg}$ & Facial trauma or deformity \\
$\mathrm{PH}$ below 7.35 & Upper airway obstruction \\
$\mathrm{PaO}_{2} / \mathrm{FiO}_{2}$ below $250 \mathrm{mmHg}$ & Inability to cooperate \\
& Airway protection \\
& Clear of secretions and saliva \\
\hline
\end{tabular}

Abbreviations: $\mathrm{FiO}_{2}$, fraction of inspired oxygen; $\mathrm{PaO}_{2}$, partial pressure of oxygen in arterial blood; $\mathrm{PaCO}_{2}$, partial pressure of carbon dioxide in arterial blood. 
support to improve sputum discharge and ventilation. Table 1 summarizes the indications for both ventilation types. ${ }^{30}$

In spite of its importance, IV should be discarded whenever appropriate to avoid time-dependent complications associated with intubation, tracheotomy, or ventilation (Table 2). ${ }^{31-33}$ To derive optimum advantages from mechanical ventilation, one should identify the optimum timing for withdrawal so that complications may be prevented while respiratory function is restored. NIV has been suggested to serve the purpose because it was identically capable in unloading respiratory muscles. ${ }^{34}$ Its application after IV also significantly reduced weaning time, alleviated ventilatorassociated complications, and improved survival. ${ }^{35-37}$ However, no consensus has yet been reached regarding the

Table 2 Complications associated with intubation, tracheotomy, or ventilation

\begin{tabular}{|c|}
\hline Common complications of intubation and tracheotomy \\
\hline Airway complications \\
\hline Laryngeal edema \\
\hline Tracheal mucosal trauma \\
\hline Contamination of the lower respiratory tract \\
\hline Loss of humidifying function of the upper airway \\
\hline Common complications of mechanical ventilation \\
\hline Mechanical complications \\
\hline Accidental disconnection \\
\hline Leaks in the ventilator circuit \\
\hline Loss of electrical power \\
\hline Loss of gas pressure \\
\hline Pulmonary complications \\
\hline Ventilator-induced lung injury \\
\hline Barotrauma \\
\hline Oxygen toxicity \\
\hline Atelectasis \\
\hline Nosocomial pneumonia \\
\hline Inflammation \\
\hline Auto-PEEP \\
\hline Asynchrony \\
\hline Acid-base complications \\
\hline Respiratory acidosis \\
\hline Respiratory alkalosis \\
\hline Cardiovascular complications \\
\hline Reduced venous return \\
\hline Reduced cardiac output \\
\hline Hypotension \\
\hline Gastrointestinal and nutritional complications \\
\hline Gastrointestinal bleeding \\
\hline Malnutrition \\
\hline Renal complications \\
\hline Reduced urine output \\
\hline Increase in antidiuretic hormone (ADH) and decrease \\
\hline in atrial natriuretic peptide (ANP) \\
\hline Neuromuscular complications \\
\hline Sleep deprivation \\
\hline Increased intracranial pressure \\
\hline Critical illness weakness \\
\hline
\end{tabular}

Abbreviation: PEEP, positive end-expiratory pressure. optimal time when NIV should replace IV. According to the Chinese Guideline for Mechanical Ventilation in Patients with Acute Exacerbation of Chronic Obstructive Pulmonary Disease 2007, weaning with T-tube is advised in COPD patients without obvious bronchial-pulmonary infection while replacement by NIV at pulmonary infection control (PIC) window is advised in COPD patients with obvious bronchial-pulmonary infection.

\section{Weaning in COPD patients without obvious bronchial-pulmonary infection}

Tobin summarized six stages in mechanical ventilatory support: 1) treatment of ARF; 2) suspicion that weaning may be possible; 3) assessment of readiness to wean; 4) spontaneous breathing trial (SBT); 5) extubation; and 6) reintubation when required. One is only liberated from IV when he successfully passes the first five steps and avoids the last.

Weaning accounts for almost half of the time in mechanical ventilation and allows resumption of spontaneous breathing after gradual reduction of mechanical support. ${ }^{38-42}$ Randomized and non-randomized historical cohort studies verified a more significant reduction in the duration of mechanical ventilation when a weaning protocol, involving weaning parameter evaluation and subsequent breathing trials, was used instead of mere clinical judgment. ${ }^{43-46}$ In view of general delays in weaning and the associated increase in mortality, ${ }^{41,47,48}$ assessment should be performed every day to allow prompt initiation of weaning.

Variations exist between protocols but weaning parameters essentially stem from observations in respiratory mechanics, gas exchange, and breathing patterns. Table 3 is a list of parameters to be considered before weaning. ${ }^{47}$ Daily screen of weaning parameters was found to have predicted a successful extubation with $82 \%$ accuracy, nearly $90 \%$ sensitivity and positive predictive values. Significance of passing the screen could also be extended to hospital survival prediction during the 1 st week and a half of mechanical ventilation. Its prognostic significance seemed to be limited though, since up to $29 \%$ of the patients failed the screen but withstood extubation. ${ }^{49}$ Thus, a successful weaning attempt does not necessarily require fulfillment of all the mentioned criteria.

SBT is usually granted to a patient who has passed the weaning assessment. SBT failure is defined by 1) objective indices such as tachypnea, tachycardia, hypertension, hypotension, hypoxemia or acidosis, and arrhythmia; 2) subjective indices such as agitation or distress, depressed mental status, diaphoresis, and evidence of increasing effort. ${ }^{47}$ Subsequently, weaning failure refers to SBT failure or the need for 
Table 3 Assessment of weaning parameters

Clinical assessment

Objective measurement
I. Adequate cough

2. Absence of excessive tracheobronchial secretion

3. Resolution of disease acute phase for which the patient was intubated

4. Clinical stability

Stable cardiovascular status (ie, fc $\leq 140$ beats/min), systolic BP $90-160 \mathrm{mmHg}$,

no or minimal vasopressors

Stable metabolic status

5. Adequate oxygenation

$\mathrm{SaO}_{2}>90 \%$ on $\mathrm{FiO}_{2} 0.4$ (or $\mathrm{PaO}_{2} / \mathrm{FiO}_{2} \geq 150 \mathrm{mmHg}$ )

PEEP $\leq 8 \mathrm{~cm} \mathrm{H}$ O

6. Adequate pulmonary function

$f_{\mathrm{R}} \leq 35$ breaths/min

MIP $\leq-20$ to $-25 \mathrm{~cm} \mathrm{H}_{2} \mathrm{O}$

$V_{\mathrm{T}}>5 \mathrm{~mL} / \mathrm{kg}$

$f_{\mathrm{R}} / V_{\mathrm{T}}<105$ breaths/min/L

No significant respiratory acidosis

7. Adequate mentation

8. No sedation or adequate mentation on sedation (or stable neurologic patient)

Abbreviations: $\mathrm{BP}$, blood pressure; fc, frequency of cardiotach; $\mathrm{FiO}_{2}$, fraction of inspired oxygen; $f_{\mathrm{R}}$, frequency of respiration; $\mathrm{MIP}$, maximal inspiratory pressure; $\mathrm{PaO}{ }_{2}$, partial pressure of oxygen in arterial blood; PEEP, positive end-expiratory pressure; $\mathrm{SaO}_{2}$, arterial oxygen saturation; $V_{\mathrm{T}}$, tidal volume.

reintubation within 48 hours of extubation. ${ }^{50,51}$ According to the number of attempts or days prior to successful weaning, patients may be classified into three groups: ${ }^{47} 1$ ) simple weaning (patients who proceeded from initiation of weaning to extubation on the first attempt without difficulty); 2) difficult weaning (patients failing the first attempt who took up to three attempts or as long as 7 days from the first SBT to achieve successful weaning); and 3) prolonged weaning (patients who failed at least three weaning attempts or required $>7$ days of weaning after the first SBT). Independent factors suggestive of prolonged weaning include COPD occurrence, ${ }^{47}$ higher $\mathrm{PaCO}_{2}$ and heart rate during the first SBT. ${ }^{52}$ Sellares et al also found a higher $\mathrm{PaCO}_{2}$ and heart rate among prolonged weaning patients before their first SBT, implying their worse condition when subjected to the initial trial. ${ }^{52}$

SBT is commonly delivered via pressure support ventilation (PSV) at $7 \mathrm{~cm} \mathrm{H}_{2} \mathrm{O}$, continuous positive airway pressure, or T-piece. A conventional protocol-directed SBT takes 120 minutes but a 30 minutes trial performed via either T-tubes or PSV was found to be equally effective in identifying successful extubations. ${ }^{44,53}$ Comparing the delivery frequency, once-daily and multiple-daily $\mathrm{T}$-piece trials were found to be equally effective. ${ }^{50}$ Consensus has also been established over the identical validity of pressure support and T-tube in SBT. ${ }^{54} \mathrm{~A}$ similar conclusion was valid among infants and children when pressure support was $10 \mathrm{~cm} \mathrm{H}_{2} \mathrm{O} .{ }^{55}$ Further to these findings, pressure support was found to overrun T-tube in difficult-to-wean patients since success of the former and failure of the latter regardlessly indicated successful extubation with unchanged reintubation rate. ${ }^{56}$ Indeed, pressure support might have surpassed T-tube because it compensated for the extra breathing workload caused by an endotracheal tube. ${ }^{57-61}$ In addition, Cabello et al observed more successful pressure support trials in difficult-to-wean patients when positive end-expiratory pressure (PEEP; $5 \mathrm{~cm}$ $\mathrm{H}_{2} \mathrm{O}$ ) was incorporated to PSV. ${ }^{62}$ This could be explained by the abilities of PEEP to 1) reduce respiratory muscle energy expenditure; ${ }^{63}$ 2) attenuate intrinsic PEEP so that the work of breathing required to trigger the ventilator reduces; $; 4,65$ and 3 ) decrease pulmonary artery occlusion pressure. ${ }^{62}$ For the past few years, computer-driven automated weaning was introduced to perform SBT automatically in intubated patients but its value remained questionable from results of different studies. ${ }^{66}$ Generally, the technology failed to facilitate weaning in surgical patients but prevailed in difficultto-wean patients, ${ }^{67}$ such as those with COPD, ischemic heart disease, and immunosuppresion. ${ }^{68,69}$

NIV has been proposed as an alternative weaning tool in COPD patients who failed SBT. According to a number of randomized controlled studies and meta-analysis, such application was associated with reduced mechanical ventilation, shortened ICU and hospital stay, decreased incidence of septic shock, and pneumonia and improved survival. . $^{35,37,70}$ Theoretically speaking, extubated patients administered with NIV should not be declared as weaning success unless they ultimately get rid of the ventilatory support. Increased use of NIV as a weaning tool thus leads to a new weaning category called "weaning in progress" wherein extubated patients continue to be supported by NIV. In spite of its benefits among COPD patients, NIV should not be indicated in all patients 
Table 4 Standard of the PIC window

\begin{tabular}{ll}
\hline Indexes & Evaluation \\
\hline Imaging change & Significantly decreased radiographic infiltrations \\
Ventilator settings & $10-12$ beats/min for SIMV \\
& $10-12 \mathrm{~cm} \mathrm{H}_{2} \mathrm{O}$ for PSV \\
Body temperature & $\leq 38^{\circ} \mathrm{C}$ \\
Leukocyte count & $<10,000 / \mathrm{mm}^{3}$ or $2,000 / \mathrm{mm}^{3}$ less than before \\
Sputum quantity & Significantly reduced \\
Lightening of sputum color & Changed to white \\
Decreased density of sputum & $<I l$ (second level) \\
\hline
\end{tabular}

Abbreviations: PIC, pulmonary infection control; PSV, pressure support ventilation; SIMV, synchronized intermittent mandatory ventilation.

failing SBT because they may be exposed to extubation failure due to substantial comorbidities. ${ }^{47}$

To summarize, the amount of time needed for IV liberation depends on a sequence of events including suspicion for weaning possibility, performance of weaning assessment, and weaning itself. In order to promptly discard ventilatory support, weaning assessment is daily performed in ventilated patients. When SBT fails in selected COPD patients, NIV may be recruited to shorten the duration of IV.

\section{Replacement of invasive ventilation by non-invasive ventilation at PIC window}

In the People's Republic of China, 80\%-90\% AECOPD cases occur as a result of bronchial-pulmonary infection. A significant proportion of them further develop into hypercapnic respiratory failure which requires invasive ventilatory support. In order to restore respiratory function and avoid time-dependent complications, studies are being conducted to search for an optimum timing to discard IV.

PIC window has been defined as a prompt stage of controlled pulmonary infection following artificial airway establishment, sputum drainage, and antibiotic administration. It was marked by thinning and decrease of sputum; clearing of sputum cloudiness; decreases in body temperature, radiographic infiltrations, and leukocytes (Table 4) $\cdot{ }^{17} \mathrm{At}$ this stage, COPD patients with severe hypercapnic respiratory failure tend to be more stable and respiratory muscle fatigue becomes relatively more significant in the development of respiratory failure. ${ }^{17}$ Wang et a $1{ }^{17}$ proposed this stage as an optimum timing to replace IV with NIV so that ventilatory insufficiency and respiratory muscle fatigue may be resolved while lower airway infection and ventilator-associated pneumonia can be avoided. Such a hypothesis was verified through a prospective cohort study and a prospective, multi-centered, randomized controlled trial among COPD patients with severe hypercapnic respiratory failure. ${ }^{71-73}$ In both research plans, the study groups were liberated from IV in exchange for NIV at PIC window while the control groups proceeded with IV throughout. By the end of the trials, the study groups were found to possess lower ventilator-associated pneumonia risks and mortality rate while requiring shorter durations of IV, ventilatory support, and ICU stay. ${ }^{17,74}$ Another study with nine patients yielded similar results except in two patients who presented with unstable hemodynamic condition and consciousness disturbance correspondingly. ${ }^{75}$

While the significance of PIC window has been verified, one should be reminded of how proper training, skills, and observation ascertain the identification of such a stage. Zhang failed to recognize PIC window in several clinical cases thus led to delay in response and subsequently compromised prognosis and increased medical costs. ${ }^{75}$ An increased intubation rate has also been associated previously with inexperienced labor among hypercapnic ARF patients. ${ }^{76,77}$ Such results suggested how proper caring and observation hold the key to the betterment of all ventilated patients above other clinical advancements.

\section{Conclusion}

Ventilatory support is essential among AECOPD patients to prevent and treat ARF. While NIV is increasingly suggested as a primary option, IV may not be avoided under certain conditions. In such cases, strategies should be implemented to discard IV as soon as possible so that time-dependent complications may not arise as a result of prolonged IV. In AECOPD patients, weaning by SBT (assisted with NIV) is suggested under insignificant bronchial-pulmonary infection while replacement by NIV at PIC window is encouraged under significant bronchial-pulmonary infection.

\section{Acknowledgments}

The work was supported by the National Key Technology R\&D Program of the 12th National Five-year Development Plan (2012BAI05B01 and 2012BAI05B02), the National 
Nature Science Foundation of China (81170056, 81400018, and 81400002), the Shanghai Committee of Science and Technology (11411951102 and 12JC1402300), and the Academic Special Science and Research Foundation for PhD Education (20130071110044).

\section{Disclosure}

The authors report no conflicts of interest in this work.

\section{References}

1. Rabe KF, Hurd S, Anzueto A, et al. Global initiative for Chronic Obstructive Lung Disease. Global strategy for the diagnosis, management, and prevention of chronic obstructive pulmonary disease: GOLD executive summary. Am J Respir Crit Care Med. 2007;176:532-555.

2. Zhong N, Wang C, Yao W, et al. Prevalence of chronic obstructive pulmonary disease in China: a large, population-based survey. Am J Respir Crit Care Med. 2007;176:753-760.

3. Tang G, Yuan F, Pang Y, et al. Survey on prevalence and risk factors of COPD in rural areas in Anhui province. Chin J Tuberc Respir Dis. 2001;24:245. Chinese.

4. Xu F, Yin XY, Zhang M, Shen H, Lu L, Xu Y. Prevalence of physiciandiagnosed COPD and its association with smoking among urban and rural residents in regional mainland China. Chest. 2005;128: $2818-2823$.

5. Liu SM, Wang XP, Wang DL, et al. Epidemiologic analysis of COPD in Guangdong province. Zhonghua Yi Xue Za Zhi. 2005;85: 747-752. Chinese.

6. Shan S, Chen B. Epidemiology investigation of chronic obstructive pulmonary disease in city and country of Tianjin. Med J Tianjin Univ. 2007;35:488-490. Chinese.

7. Zielinski J, MacNee W, Wedzicha J, et al. Causes of death in patients with COPD and chronic respiratory failure. Monaldi Arch Chest Dis. 1997;52:43-47.

8. Peters DK, Kochanek DK, Murphy SL. Deaths: final data for 1996. Natl Vital Stat Rep. 1998;47-100.

9. Higgins MW, Thom T. Incidence, prevalence and mortality: intra- and inter-country difference. In: Hensley MJ, Saunders NA, editors. Clinical Epidemiology of Chronic Obstructive Pulmonary Disease. New York: Marcel Dekker, 1990;23-43.

10. Connors AF Jr, Dawson NV, Thomas C, et al. Outcomes following acute exacerbation of severe chronic obstructive lung disease. The SUPPORT investigators (Study to Understand Prognoses and Preferences for Outcomes and Risks of Treatment). Am J Respir Crit Care Med. 1996;154:959-967.

11. Fuso L, Incalzi RA, Pistelli R, et al. Predicting mortality of patients hospitalized for acutely exacerbated chronic obstructive pulmonary disease. Am J Med. 1995;98:272-277.

12. Anthonisen NR, Manfreda J, Warren CP, Hershfield ES, Harding GK, Nelson NA. Antibiotic therapy in exacerbations of chronic obstructive pulmonary disease. Ann Intern Med. 1987;106:196-204.

13. Paggiaro PL, Dahle R, Bakran I, Frith L, Hollingworth K, Efthimiou J. Multicentre randomised placebo-controlled trial of inhaled fluticasone proprionate in patients with chronic obstructive pulmonary disease. Lancet. 1998;351:73-80.

14. Burge PS, Calverley PM, Jones PW, Spencer S, Anderson JA, Maslen TK. Randomised, double blind, placebo controlled study of fluticasone propionate in patients with moderate to severe chronic obstructive pulmonary disease: the ISOLDE trial. BMJ. 2000;320:1297-1303.

15. Wedzicha JA, Donaldson GC. Exacerbations of chronic obstructive pulmonary disease. Respir Care. 2003;48:1204-1213.

16. Borrell E, Rodríguez M, Torán $\mathrm{P}$, et al. Incidence and risk factors of exacerbations among COPD patients in primary health care: APMPOC study. BMC Public Health. 2009;9:8.
17. Wang C, Shang M, Huang K, et al. Sequential non-invasive mechanical ventilation following short-term invasive mechanical ventilation in COPD induced hypercapnic respiratory failure. Chin Med J (Engl). 2003;116:39-43.

18. Miravitlles M, Murio C, Guerrero T. Factors associated with relapse after ambulatory treatment of acute exacerbations of chronic bronchitis, DAFNE Study Group. Eur Respir J. 2001;17:928-933.

19. Viegi G, Maio S, Pistelli F, Baldacci S, Carrozzi L. Epidemiology of chronic obstructive pulmonary disease: health effects of air pollution. Respirology. 2006;11:523-532.

20. American Thoracic Society Statement. Standards for the diagnosis and care of patients with chronic obstructive pulmonary disease. Am J Respir Crit Care Med. 1995;152:S77-S120.

21. Seneff MG, Wagner DP, Wagner RP, Zimmerman JE, Knaus WA. Hospital and 1-year survival of patients admitted to intensive care units with acute exacerbation of chronic obstructive pulmonary disease. JAMA. 1995;274:1852-1857.

22. Bach PB, Brown C, Gelfand SE, McCrory DC; American College of Physicians-American Society of Internal Medicine; American College of Chest Physicians. Management of acute exacerbations of chronic obstructive pulmonary disease: a summary and appraisal of published evidence. Ann Intern Med. 2001;134:600-620.

23. Patil SP, Krishnan JA, Lechtzin N, Diette GB. In-hospital mortality following acute exacerbations of chronic obstructive pulmonary disease. Arch Intern Med. 2003;163:1180-1186.

24. Tabak YP, Sun X, Johannes RS, Gupta V, Shorr AF. Mortality and need for mechanical ventilation in acute exacerbations of chronic obstructive pulmonary disease: development and validation of a simple risk score. Arch Intern Med. 2009;169(17):1595-1602.

25. Ambrosino N, Vagheggini G. Non-invasive ventilation in exacerbations of COPD. Int J Chron Obstruct Pulmon Dis. 2007;2(4):471-476.

26. Farah R, Makhoul N. Optimal time needed for withdrawal of mechanical ventilation in patients with chronic obstructive pulmonary disease. Isr Med Assoc J. 2011;13(10):609-612.

27. Rodrìguez-Roisin R. COPD exacerbations-5: management. Thorax. 2006;61:535-444.

28. Brochard L, Isabey D, Piquet J, et al. Reversal of acute exacerbations of chronic obstructive lung disease by inspiratory assistance with a face mask. N Engl J Med. 1990;323:1523-1530.

29. García Vicente E, Sandoval Almengor JC, Díaz Caballero LA, Salgado Campo JC. Invasive mechanical ventilation in COPD and asthma. Med Intensiva. 2011;35:288-298.

30. Pelosi P, Jaber S. Noninvasive respiratory support in the perioperative period. Curr Opin Anaesthesiol. 2010;23:233-238.

31. Fagon JY, Chastre J, Domart Y, et al. Nosocomial pneumonia in patients receiving continuous mechanical ventilation. Prospective analysis of 52 episodes with use of a protected specimen brush and quantitative culture techniques. Am Rev Respir Dis. 1989;139:877-884.

32. Pingleton SK. Complications of acute respiratory failure. Am Rev Respir Dis. 1988;137:1463-1493.

33. Hess DR, MacIntyre NR. Mechanical ventilation. In: Hess DR, MacIntyre N, Mishoe S, et al. editors. Respiratory Care: Principles and Practice. Massachusetts: Jones and Bartlett Publishers. 2011;462-500.

34. Vitacca M, Ambrosino N, Clini E, et al. Physiological response to pressure support ventilation delivered before and after extubation in COPD patients not capable of totally spontaneous autonomous breathing. Am J Respir Crit Care Med. 2001;164:638-641.

35. Nava S, Ambrosino N, Clini E, et al. Noninvasive mechanical ventilation in the weaning of patients with respiratory failure due to chronic obstructive pulmonary disease. Ann Intern Med. 1998;128:721-728.

36. Girault C, Daudenthun I, Chevron V, Tamion F, Leroy J, Bonmarchand G. Noninvasive ventilation as a systematic extubation and weaning technique in acute-on-chronic respiratory failure. Am J Respir Crit Care Med. 1999;160:86-92.

37. Budweiser S, Baur T, Jörres RA, Kollert F, Pfeifer M, Heinemann F. Noninvasive ventilation during persisting weaning failure. Am J Respir Crit Care Med. 2003;168:70-76. 
38. Esteban A, Alía I, Ibañez J, Benito S, Tobin MJ. Modes of mechanical ventilation and weaning. A national survey of Spanish hospitals. The Spanish Lung Failure Collaborative Group. Chest. 1994;106: 1188-1193.

39. Esteban A, Ferguson ND, Meade MO, et al. Evolution of mechanical ventilation in response to clinical research. Am J Respir Crit Care Med. 2008;177:170-177.

40. Ely EW, Baker AM, Dunagan DP, et al. Effect on the duration of mechanical ventilation of identifying patients capable of breathing spontaneously. N Engl J Med. 1996;335:1864-1869.

41. Esteban A, Anzueto A, Frutos F, et al. Characteristics and outcomes in adult patients receiving mechanical ventilation: a 28-day international study. JAMA. 2002;287(3):345-355.

42. Lemaire F, Teboul JL, Cinotti L, et al. Acute left ventricular dysfunction during unsuccessful weaning from mechanical ventilation. Anesthesiology. 1988;69:171-179.

43. Epstein SK, Ciubotaru RL, Wong JB. Effect of failed extubation on the outcome of mechanical ventilation. Chest. 1997;112:186-192.

44. Esteban A, Alía I, Tobin MJ, et al. Effect of spontaneous breathing trial duration on outcome of attempts to discontinue mechanical ventilation. Spanish Lung Failure Collaborative Group. Am J Respir Crit Care Med. 1999;159:512-518.

45. Zilberberg MD, de Wit M, Pirone JR, Shorr AF. Growth in adult prolonged acute mechanical ventilation: implications for healthcare delivery. Crit Care Med. 2008;36:1451-1455.

46. Epstein SK, Ciubotaru RL. Independent effects of etiology of failure and time to reintubation on outcome for patients failing extubation. Am J Respir Crit Care Med. 1998;158:489-493.

47. Boles JM, Bion J, Connors A, et al. Weaning from mechanical ventilation. Eur Respir J. 2007;29:1033-1056.

48. Coplin WM, Pierson DJ, Cooley KD, Newell DW, Rubenfeld GD. Implications of extubation delay in brain-injured patients meeting standard weaning criteria. Am J Respir Crit Care Med. 2000;161:1530-1536.

49. Ely EW, Baker AM, Evans GW, Haponik EF. The prognostic significance of passing a daily screen of weaning parameters. Intensive Care Med. 1999;25:581-587.

50. Esteban A, Frutos F, Tobin MJ, et al. A comparison of four methods of weaning patients from mechanical ventilation. Spanish Lung Failure Collaborative Group. N Engl J Med. 1995;332:345-350.

51. Vallverdú I, Calaf N, Subirana M, Net A, Benito S, Mancebo J. Clinical characteristics, respiratory functional parameters, and outcome of a two-hour T-piece trial in patients weaning from mechanical ventilation. Am J Respir Crit Care Med. 1998;158:1855-1862.

52. Sellares J, Ferrer M, Cano E, Loureiro H, Valencia M, Torres A. Predictors of prolonged weaning and survival during ventilator weaning in a respiratory ICU. Intensive Care Med. 2011;37:775-784.

53. Perren A, Domenighetti G, Mauri S, Genini F, Vizzardi N. Protocoldirected weaning from mechanical ventilation: clinical outcome in patients randomized for a 30-min or 120-min trial with pressure support ventilation. Intensive Care Med. 2002;28:1058-1063.

54. Richard C, Beydon L, Cantagrel S, et al. Weaning from mechanical ventilation. Consensus recommendations. Reanimation. 2001;10:697-698.

55. Farias JA, Retta A, Alía I, et al. A comparison of two methods to perform a breathing trial before extubation in pediatric intensive care patients. Intensive Care Med. 2001;27:1649-1654.

56. Ezingeard E, Diconne E, Guyomarch S, et al. Weaning from mechanical ventilation with pressure support in patients failing a T-tube trial of spontaneous breathing. Intensive Care Med. 2006;32:165-169.

57. Fiastro JF, Habib MP, Quan SF. Pressure support compensation for inspiratory work due to endotracheal tubes and demand continuous positive airway pressure. Chest. 1988;93:499-505.

58. Straus C, Louis B, Isabey D, Lemaire F, Harf A, Brochard L. Contribution of the endotracheal tube and the upper airway to breathing workload. Am J Respir Crit Care Med. 1998;157:23-30.

59. Brochard L, Rua F, Lorino H, Lemaire F, Harf A. Inspiratory pressure support compensates for the additional work of breathing caused by the endotracheal tube. Anesthesiology. 1991;75:739-745.
60. Kuhlen R, Max M, Dembinski R, Terbeck S, Jürgens E, Rossaint R Breathing pattern and workload during automatic tube compensation, pressure support and T-piece trials in weaning patients. Eur J Anaesthesiol. 2003;20:10-16.

61. Conti G, De Blasi RA, Lappa A, et al. Evaluation of respiratory system resistance in mechanically ventilated patients: the role of the endotracheal tube. Intensive Care Med. 1994;20:421-424.

62. Cabello B, Thille AW, Roche-Campo F, Brochard L, Gómez FJ, Mancebo J. Physiological comparison of three spontaneous breathing trials in difficult-to-wean patients. Intensive Care Med. 2010;36: 1171-1179.

63. Sassoon CS, Light RW, Lodia R, Sieck GC, Mahutte CK. Pressure-time product during continuous positive airway pressure, pressure support ventilation, and T-piece during weaning from mechanical ventilation. Am Rev Respir Dis. 1991;143:469-475.

64. Mancebo J, Albaladejo P, Touchard D, et al. Airway occlusion pressure to titrate positive end-expiratory pressure in patients with dynamic hyperinflation. Anesthesiology. 2000;93:81-90.

65. Smith TC, Marini JJ. Impact of PEEP on lung mechanics and work of breathing in severe airflow obstruction. J Appl Physiol. 1988;65(4):1488-1499.

66. Dojat M, Harf A, Touchard D, Lemaire F, Brochard L. Clinical evaluation of a computer-controlled pressure support mode. Am J Respir Crit Care Med. 2000;161:1161-1166.

67. Rose L, Presneill JJ, Johnston L, Cade JF. A randomised, controlled trial of conventional versus automated weaning from mechanical ventilation using SmartCareTM/PS. Intensive Care Med. 2008;34: 1788-1795.

68. Lellouche F, Mancebo J, Jolliet P, et al. A multicenter randomized trial of computer-driven protocolized weaning from mechanical ventilation. Am J Respir Crit Care Med. 2006;174:894-900.

69. Liu L, Xu XT, Yang Y, Huang YZ, Liu SQ, Qiu HB. Computer-driven automated weaning reduces weaning duration in difficult-to-wean patients. Chin Med J. 2013;126:1814-1818.

70. Burns KE, Adhikari NK, Meade MO. A meta-analysis of noninvasive weaning to facilitate liberation from mechanical ventilation. Can J Anaesth. 2006;53:305-315.

71. Kollef MH. Avoidance of tracheal intubation as a strategy to prevent ventilator-associated pneumonia. Intensive Care Med. 1999;25: $553-555$.

72. Nourdine K, Combes P, Carton MJ, Beuret P, Cannamela A, Ducreux JC. Does noninvasive ventilation reduce the ICU nosocomial infection risk? A prospective clinical survey. Intensive Care Med. 1999;25: 567-573.

73. Plant PK, Eliott MW. Non-invasive ventilation in acute exacerbations of COPD. Q J Med. 1998;91:657-660.

74. Collaborating Research Group for Noninvasive Mechanical Ventilation of Chinese Respiratory Society. Pulmonary infection control window in treatment of severe respiratory failure of chronic obstructive pulmonary diseases: a prospective, randomized controlled, multi-centred study. Chin Med J (Engl). 2005;118(19):1589-1594.

75. Zhang X. Pulmonary infection control window as a switching point for consequential ventilation: an encouraging finding in treatment of acute respiratory failure of chronic obstructive pulmonary disease. Chin Med $J$ (Engl). 2005;118(19):1587-1588.

76. Carlucci A, Delmastro M, Rubini F, Fracchia C, Nava S. Changes in the practice of non-invasive ventilation in treating COPD patients over 8 years. Intensive Care Med. 2003;29:419-425.

77. Nouira S, Marghli S, Belghith M, Besbes L, Elatrous S, Abroug F. Once daily oral ofloxacin in chronic obstructive pulmonary disease exacerbation requiring mechanical ventilation: a randomized placebocontrolled trial. Lancet. 2001;358:2020-2025. 


\section{Publish your work in this journal}

The International Journal of COPD is an international, peer-reviewed journal of therapeutics and pharmacology focusing on concise rapid reporting of clinical studies and reviews in COPD. Special focus is given to the pathophysiological processes underlying the disease, intervention programs, patient focused education, and self management protocols.

This journal is indexed on PubMed Central, MedLine and CAS. The manuscript management system is completely online and includes a very quick and fair peer-review system, which is all easy to use. Visit http://www.dovepress.com/testimonials.php to read real quotes from published authors.

Submit your manuscript here: http://www.dovepress.com/international-journal-of-chronic-obstructive-pulmonary-disease-journal 